\title{
Caffeine-clozapine interaction associated with severe toxicity and multiorgan system failure: a case report
}

\author{
Alex Yartsev $^{1 *}$ (D) and Carmelle Peisah ${ }^{1,2}$
}

\begin{abstract}
Background: Caffeine is a known inhibitor of Clozapine metabolism mediated by inhibition of CYP1A2. Hitherto, the effects of caffeine on Clozapine levels have always been modest, as have the clinical manifestations of toxicity resulting from their interaction. We present a case of severe toxicity associated with the co-consumption of caffeine and Clozapine culminating in life-threatening complications requiring management in Intensive Care.

Case presentation: A 34 year old male with a history of chronic schizophrenia, who had been managed stably on $400 \mathrm{mg}$ Clozapine for the previous 5 years, changed his dietary behaviour and began consuming caffeinecontaining energy drinks over the course of 3 weeks. The total daily dose of caffeine was estimated as $600 \mathrm{mg} /$ day (four cans of Red Bull). He subsequently presented to the Emergency Department with life-threatening Clozapine toxicity, resulting in a decreased level of consciousness, severe metabolic acidosis, acute respiratory failure, raised inflammatory markers and acute renal failure attributed to interstitial nephritis. Maximum recorded Clozapine level was $1796 \mathrm{ng} / \mathrm{ml}$.
\end{abstract}

Conclusions: This case describes the interaction between a common caffeine-containing beverage and a commonly prescribed antipsychotic medication, associated with severe adverse effects. We call for clinical and scientific attention to the possible interaction between these substances and draw attention to the implications for prescribing practices and patient counselling.

Keywords: Clozapine, Caffeine, Interaction, Multiorgan system failure, Case report

\section{Background}

Clozapine is a commonly prescribed medication indicated for the management of treatment-resistant schizophrenia, with a worldwide pattern of increasing use [13]. Clozapine is a dibenzazepine derivative which is metabolised predominantly by the liver, the two principal metabolites being desmethylClozapine and Clozapine $\mathrm{N}$-oxide. The demethylation of Clozapine which produces desmethylClozapine is performed by CYP1A2 [4]. Caffeine inhibits the metabolism of Clozapine, probably

\footnotetext{
* Correspondence: alex.yartsev@health.nsw.gov.au

1 Westmead Hospital Intensive Care Unit, Sydney, Australia

Full list of author information is available at the end of the article
}

by inhibition of CYP1A2. The effect of caffeine on Clozapine levels in studies of healthy volunteers has always been modest. For example, serum Clozapine levels increased by only $19 \%$ following co-administration of Clozapine $(12.5 \mathrm{mg})$ and caffeine $(100 \mathrm{mg})$ in healthy young adults $[5,6]$. Further, the clinical manifestations of toxicity resulting from the interaction of Clozapine and caffeine hitherto described have been similarly relatively mild and have included stiffness, abrupt onset of arousal and exacerbation of psychosis, all of which were easily reversible [6, 7]. However, significant interindividual variability exists in pharmacokinetics of commonly used antipsychotics ${ }^{8}$. The aforementioned case studies report a Clozapine dose of $200 \mathrm{mg}$ and a caffeine dose of 425 -

(c) The Author(s). 2021 Open Access This article is licensed under a Creative Commons Attribution 4.0 International License, which permits use, sharing, adaptation, distribution and reproduction in any medium or format, as long as you give appropriate credit to the original author(s) and the source, provide a link to the Creative Commons licence, and indicate if changes were made. The images or other third party material in this article are included in the article's Creative Commons licence, unless indicated otherwise in a credit line to the material. If material is not included in the article's Creative Commons licence and your intended use is not permitted by statutory regulation or exceeds the permitted use, you will need to obtain permission directly from the copyright holder. To view a copy of this licence, visit http://creativecommons.org/licenses/by/4.0/ The Creative Commons Public Domain Dedication waiver (http://creativecommons.org/publicdomain/zero/1.0/) applies to the data made available in this article, unless otherwise stated in a credit line to the data. 
$850 \mathrm{mg} /$ day in one scenario [7] and a Clozapine dose of $550 \mathrm{mg}$ with a caffeine intake of $200 \mathrm{mg} / \mathrm{d}$ the other [6]. We are unaware of any previous reports of severe, lifethreatening interactions between caffeine and Clozapine. We present a case of a patient with chronic schizophrenia managed with a stable long-term dose of Clozapine who presented with severe Clozapine toxicity culminating in multisystem organ failure due to a change in caffeine intake. While this severe adverse interaction is unusual, consumption of high energy drinks is part of a raft of poor nutritional habits often associated with serious mental illness such as schizophrenia both in a chronic state [8-10], as well as a manifestation of relapse $[11,12]$. Hence, the importance of shedding light on this case.

\section{Case presentation}

A 35 year-old male was brought to the emergency department by ambulance after being found unconscious in his home.

\section{History of presenting complaint}

He was last seen to be alert twenty-four hours prior. On the day of his presentation, his carer found him sitting slumped against the wall on the floor, obtunded and tachypnoeic. The ambulance officers made a note of "energy drinks spread over living room table" in his home. At triage in the emergency department, his respiratory rate was 50 , heart rate 110 , non-invasive systolic blood pressure $129 \mathrm{mmHg}$. Glasgow coma score (GCS) was initially scored as $14(\mathrm{E}=4 \mathrm{~V}=4 \mathrm{M}=6)$ and the blood sugar level (BSL) was $32.5 \mathrm{mmol} / \mathrm{L}$. A tympanic temperature of $38.0 \mathrm{C}$ was recorded. Arterial blood gas analysis revealed a profound metabolic acidosis with $\mathrm{pH}$ of 6.91, $\mathrm{PaCO}_{2} 44 \mathrm{mmHg}, \mathrm{HCO}_{3}{ }^{-} 10$, lactate of 6.2 , and an anion gap of $26 \mathrm{mmol} / \mathrm{L}$. Point-of-care testing revealed a serum ketone level of 3.0. Given the raised BSL and decreased level of consciousness, a provisional diagnosis of hyperosmolar hyperglycaemic syndrome with diabetic ketoacidosis was made. Shortly after triage, the patient's level of consciousness deteriorated, with a GCS score of $6(\mathrm{E}=1 \mathrm{~V}=1 \mathrm{M}=4)$. He was intubated and transferred to the Intensive Care Unit (ICU). A urine drug screen was obtained prior to the intubation, and was negative for all tested substances (amphetamine, cannabis, cocaine, MDMA, benzodiazepines and opiates).

\section{Progress during ICU admission}

Over the subsequent 2 days of his stay in the ICU, the patient remained unconscious with minimal sedation, and dependent on mechanical ventilation. He required modest ventilator support and his fraction of inspired oxygen $\left(\mathrm{FiO}_{2}\right)$ was weaned to 0.3 within the first twentyfour hours.

He remained stable haemodynamically, and did not require any vasoactive agents to support his blood pressure. During the first 2 days of ICU admission he remained febrile and a significant inflammatory marker rise was observed, with a CRP of $520 \mathrm{mg} / \mathrm{L}$ and a procalcitonin of $13.21 \mu \mathrm{g} / \mathrm{L}$, rising at maximum over his course of stay to $40.77 \mu \mathrm{g} / \mathrm{L}$. As septic shock was suspected, empiric antimicrobial therapy with meropenem $(1 \mathrm{~g}$ every 8 h) was commenced. He underwent a computed tomography scan $(\mathrm{CT})$ of the head, chest, abdomen and pelvis, which did not reveal any foci of infection. Specifically, no structural abnormality of the kidneys was detected, nor any changes in the lungs which might have been associated with aspiration pneumonia. Blood cultures and urine cultures did not yield any pathogenic organisms, and COVID-19 PCR was negative. Meropenem was ceased on the third day of admission, as there remained no clinical features of infection.

As the patient had become anuric and was developing clinically significant fluid overload, a vas cath was placed and continuous renal replacement therapy was commenced (continuous veno-venous haemodiafiltration, CVVHDF). As the serum Clozapine level taken on admission to the emergency department had now became available $(1796 \mathrm{ng} / \mathrm{ml})$, Clozapine-induced interstitial nephritis was raised as a possibility, and a trial of intravenous methylprednisolone was commenced empirically (as the patient's morbidly obese body habitus did not lend itself to a safe renal biopsy). Methylprednisolone ( $250 \mathrm{mg}$ daily) was used for a total duration of 5 days.

After day three of ICU admission, the patient had regained consciousness, and was able to obey simple commands. Having been commenced on olanzapine earlier in the admission for agitation, this was weaned and ceased and aripiprazole ( $5 \mathrm{mg}$ daily) commenced via NGT (ie prior to extubation) chosen for its safest use in renal failure and in hyperglycaemia. This was welltolerated and continued for the remainder of his admission.

After fluid removal by haemofiltration the patient was extubated on Day 4 of ICU admission, with no further respiratory sequelae. At this stage, the Clozapine level had decreased to $926 \mu \mathrm{g} / \mathrm{L}$. (see Fig. 1).

\section{Past medical and surgical history}

The patient had a background history of morbid obesity (weight = $142 \mathrm{~kg} ;$ BMI $48.9 \mathrm{~kg} / \mathrm{m}^{2}$ ), childhood asthma, gastro-oesophageal reflux disease, hypercholesterolaemia and impaired glucose tolerance. His regular medications consisted of Clozapine $400 \mathrm{mg}$ nocte, esomeprazole 20 $\mathrm{mg}$ mane, atorvastatin $10 \mathrm{mg}$ nocte, and metformin 500 mg nocte. He was a lifelong non-smoker, and consumed 


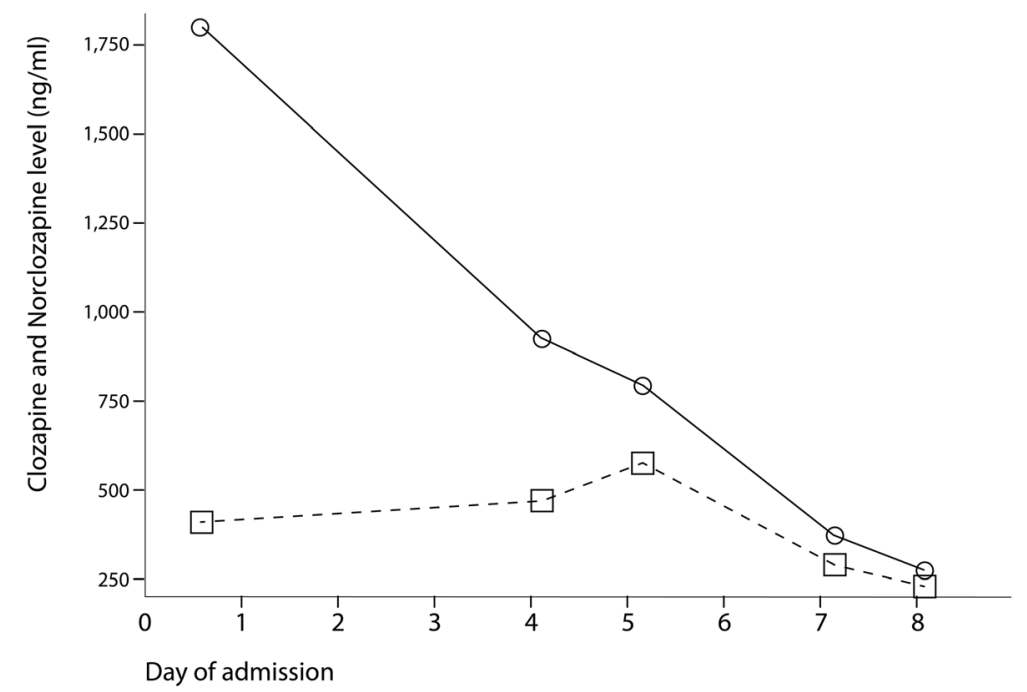

Fig. 1 "Clozapine level and NorClozapine level". Solid line: Clozapine level. Dashed line: norClozapine level

alcohol every day (4 beers, or approximately $60 \mathrm{~g}$ of ethanol per day) until the week prior to presentation (see below).

\section{Past psychiatric history}

The patient was commenced on Clozapine (400 mg nocte) 2 years prior to these events, following a prolonged inpatient admission to a mental health facility during which several other agents were trialled unsuccessfully. His psychiatrist confirmed that on Clozapine the patient had remained stable with no relapses and regular clinic attendance. Clozapine levels in the community had been within the normal therapeutic range.

Prior to presentation he had been living alone and working as a cleaner up until the COVID pandemic. He was relatively independent in activities of daily living, although received assistance weekly with grocery shopping from a support worker. He self- administered medications and Clozapine levels had been stable during outpatient therapy, as had been his haematological indices on regular screening, with the exception of mildly reduced lymphocytes at times (with preservation of neutrophil levels). These historical data suggest that this patient was not suffering from any cardiovascular or immunological complications of Clozapine therapy which might otherwise explain his presentation and multiorgan system failure.

\section{Mental status examination}

Upon review of his mental status following extubation, the patient was appropriate with euthymic mood and bright, reactive affect. There was no evidence of active psychotic symptoms (i.e. no thought disorder, no perceptual abnormalities nor abnormalities of content) or delirium. He denied any suicidal ideation either crosssectionally or prior to presentation, and rather reported usual compliance with his medication in the weeks leading up to his presentation. He demonstrated good insight and judgement, including help seeking and wanting to remain on psychotropics. According to his own account, during the week before admission, he had decreased his intake of alcohol to zero, while increasing his intake of energy drinks to achieve weight loss with his daily consumption of caffeine fluctuating between 150 and $450 \mathrm{mg} /$ day (between two and six $250 \mathrm{ml}$ cans of Red Bull per day, with a caffeine concentration of 30 $\mathrm{mg} / 100 \mathrm{ml})$.

\section{Progress and outcome}

The patient was discharged from the ICU after ten days. Methylprednisolone had transitioned to oral prednisolone, the dose of which was weaned gradually over 3 weeks, and ceased. Other complications of his stay included a left lower limb DVT and HITS, which had required intravenous bivalirudin as a bridge to warfarin therapy. His renal function remained impaired following discharge from the ICU, and renormalised only after fourteen days. He was discharged home after a total hospital stay of twenty-seven days. On consultation with the patient and his regular psychiatrist, aripiprazole was continued instead of Clozapine as his regular therapy.

\section{Discussion and conclusions}

This case describes significant morbidity associated with Clozapine toxicity, which most likely resulted from the interaction between Clozapine and caffeine in an otherwise stable patient with chronic schizophrenia. 
Clozapine is a known cause of acute interstitial nephritis [13], which manifests as acute kidney injury characterised by the histological finding of inflammatory oedema in the tubulointerstitium of the kidney. Although it is usually described in association with fever, skin rash, and eosinophilia, in reality only a minority of patients demonstrate these "classic" features [14]. Case reports of Clozapine-induced acute interstitial nephritis generally describe renal impairment of subacute onset in stable patients undergoing outpatient treatment [13]. Only one case of Clozapine-induced nephritis required intermittent haemodialysis [15].

Clozapine use per se is also a known cause of elevated inflammatory markers and fever, although this phenomenon is usually associated with Clozapineinduced myocarditis. The presence of CRP elevation in association with Clozapine therapy and without myocarditis is also known from case reports $[16,17]$ where a modest CRP elevation was observed (55.4-122 mg/L). However, in this case, the patient remained febrile for forty-eight hours with temperatures exceeding $39.0 \mathrm{C}$ and had a CRP value of $520 \mathrm{mg} / \mathrm{L}$, more consistent with sepsis. Similarly, a modestly elevated procalcitonin has been reported in association with Clozapine use [18] although in this case, procalcitonin levels were in a range usually associated with severe septic shock. Nothwithstanding this, the only positive peripheral blood culture was collected at the time of his admission to the ED, and had grown S.epidermitis, which was dismissed as a contaminant.

The other manifestation of severe Clozapine toxicity illustrated here was hyperosmolar hyperglycaemic syndrome with diabetic ketoacidosis, to which the patient was likely prone given his pre-existing metabolic syndrome and Clozapine use [19, 20]. These pre-existing conditions distinguish patients with schizophrenia on long-term antipsychotics such as Clozapine from healthy young adults - upon whom some of the drug interaction studies have been based - and go towards explaining the severity of the toxicity seen in this case.

The risk of drug interaction - not only involving therapeutic drugs but also recreational agents such as caffeine - must be taken into account when prescribing antipsychotic agents to patients with schizophrenia. This is all the more so because the consumption of caffeinated beverages- whether it be in the form of energy drinks, diet drinks or coffee - is almost ubiquitous and often perceived as harmless by patients. Moreover, the desire to lose weight - the driver in this case - is a natural and desirable response to the weight gain associated with antipsychotic drug use. However, the question remains: how much is "significant amounts of caffeine?" For example, Ellison and Dufresne suggested that caffeine can appreciably inhibit CYP1A2 with the equivalent of three cups of coffee per day [21], or approximately $3 \mathrm{mg} / \mathrm{kg}$ of caffeine. More conservatively, de Leon referred to "dramatic changes in caffeine intake" by more than one cup of coffee or two cans of caffeinated soda [22]. By removing caffeine (on average $162 \mathrm{mg} /$ day) from the diet of patients who were receiving Clozapine monotherapy (271 +/- $102 \mathrm{mg} /$ day) and neither alcohol nor any other medication, Carillo et al. [23] were able to reduce Clozapine levels by $46 \%$ (from 486 to $306 \mathrm{ng} /$ $\mathrm{mL}$ ). Given the interindividual variability in pharmacokinetics [24] there is no definitive answer, other than to arm the patient with the information and risks.

This case of severe Clozapine toxicity may not be attributed entirely to the interaction between Clozapine and caffeine. Clozapine is a substrate for multiple CYP450 enzymes, which include CYP2D6 and CYP3A4 as well as the CYP1A2 pathway affected by caffeine [4]. The patient was also regularly prescribed atorvastatin (10 mg nocte) which is known to inhibit CYP3A4 [25], esomeprazole (20 mg mane) which is not known to inhibit CYP450 enzymes [26] but which may compete with Clozapine as a substrate for CYP3A4, and metformin which does not undergo hepatic metabolism. The doses of these regular medications had remained unchanged for at least 12 months prior to this presentation, during which time the patient had stable Clozapine levels, which makes it unlikely that an atorvastatin-Clozapine interaction had contributed significantly to this sudden onset of severe toxicity. Esomeprazole, by acting as a competitive substrate for CYP3A4, may have contributed to Clozapine toxicity by eliminating this alternative pathway of metabolism, when clearance by the CYP1A2 pathway became unavailable. The patient had also been drinking up to 4 standard drinks of alcohol per day up util 1 week prior to his presentation. Ethyl alcohol is a known inducer of CYP3A4 [27], and the withdrawal of this effect (resulting in reduced CYP3A4 activity) could have contributed to decreased Clozapine clearance by increasing the reliance on the CYP1A2 pathway, which is inhibited by caffeine.

Patient education regarding the potential for drug interaction with specific enquiry into caffeine consumption should form a routine part of psychiatric clinical practice. The severity of the manifestations of Clozapine toxicity resulting from co-consumption of significant amounts of caffeine behoves us to warn our patients of this potential for serious harm from these interactions. Caffeine is not worth dying for.

\section{Abbreviations}

ICU: Intensive Care Unit; GCS: Glasgow Coma Scale; BSL: Blood Sugar Level; SBE: Standard Base Excess; CWHDF: Continuous Veno-Venous HaemoDiaFiltration; NGT: NasoGastric Tube; HITS: Heparin-Induced Thrombocytopenia Syndrome; DVT: Deep Venous Thrombosis 


\section{Acknowledgements}

The authors acknowledge the contribution of Ms. Angela Netluch (Clinical Pharmacist) for her contribution to the care of this patient, for identifying the drug interaction, and for her assistance with the manuscript.

\section{Authors' contributions}

AY was the primary ICU consultant treating the patient, was corresponding author of the manuscript, and wrote the manuscript. CP was one of the consultant psychiatrists involved in his care and contributed to the writing of the manuscript. All authors have read and approved the manuscript.

\section{Funding}

The authors received no funding to support this publication.

\section{Availability of data and materials}

Patient data supporting the results reported in the article can be obtained from the corresponding author by email.

\section{Declarations}

\section{Ethics approval and consent to participate}

The patient has given his written consent for the publication of de-identified case information regarding his medical condition and its management

\section{Consent for publication}

The patient has given his written consent for the publication of de-identified case information regarding his medical condition and its management

\section{Competing interests}

The authors declare that they have no competing interests

\section{Author details}

${ }^{1}$ Westmead Hospital Intensive Care Unit, Sydney, Australia. ${ }^{2}$ University New South Wales, Sydney, Australia.

Received: 23 November 2020 Accepted: 5 April 2021

Published online: 13 April 2021

\section{References}

1. Xu SW, Dong M, Zhang Q, Yang SY, Chen LY, Sim K, et al. Clozapine prescription pattern in patients with schizophrenia in Asia: the REAP survey (2016). Psychiatry Res. 2020;287:112271. https://doi.org/10.1016/j.psychres.2 019.02.056.

2. Bachmann CJ, Aagaard L, Bernardo M, Brandt L, Cartabia M, Clavenna A, et al. International trends in clozapine use: a study in 17 countries. Acta Psychiatr Scand. 2017;136(1):37-51. https://doi.org/10.1111/acps.12742.

3. Siskind DJ, Harris M, Phillipou A, Morgan VA, Waterreus A, Galletly C, et al. Clozapine users in Australia: their characteristics and experiences of care based on data from the 2010 National Survey of high impact psychosis. Epidemiol Psychiatric Sci. 2017;26(3):325-37. https://doi.org/10.1017/S204 5796016000305

4. Pirmohamed M, Williams D, Madden S, Templeton E, Park BK. Metabolism and bioactivation of clozapine by human liver in vitro. J Pharmacol Exp Ther. 1995;272(3):984-90

5. Hägg S, Spigset O, Mjörndal T, Dahlqvist R. Effect of caffeine on clozapine pharmacokinetics in healthy volunteers. Br J Clin Pharmacol. 2000;49(1):5963. https://doi.org/10.1046/j.1365-2125.2000.00111.x.

6. Odom-White A, de Leon J. Clozapine levels and caffeine. J Clin Psychiatry. 1996;57(4):175-6.

7. Vainer JL, Chouinard G. Interaction between caffeine and clozapine. J Clin Psychopharmacol. 1994;14(4):284-5. https://doi.org/10.1097/00004714-1994 08000-00014.

8. Bogomolova S, Zarnowiecki D, Wilson A, Fielder A, Procter N, Itsiopoulos C, et al. Dietary intervention for people with mental illness in South Australia. Health Promot Int. 2018;33(1):71-83. https://doi.org/10.1093/heapro/daw055.

9. Rihs M, Muller C, Baumann P. Caffeine consumption in hospitalized psychiatric patients. Eur Arch Psychiatry Clin Neurosci. 1996;246(2):83-92. https://doi.org/10.1007/BF02274898.

10. Kruger A. Chronic psychiatric patients' use of caffeine: pharmacological effects and mechanisms. Psychol Rep. 1996;78(3):915-23. https://doi.org/1 0.2466/pro.1996.78.3.915.
11. Cerimele JM, Stern AP, Jutras-Aswad D. Psychosis following excessive ingestion of energy drinks in a patient with schizophrenia. Am J Psychiatry. 2010;167(3):353.

12. Menkes DB. Transient psychotic relapse temporally related to ingestion of an "energy drink". Med J Aust. 2011;194(4):206. https://doi.org/10.5694/j.132 6-5377.2011.tb03777.x.

13. Chan SY, Cheung CY, Chan PT, Chau KF. Clozapine-induced acute interstitial nephritis. Hong Kong Med J. 2015;21(4):372-4. https://doi.org/10.12809/ hkmj144312.

14. Clarkson MR, Giblin L, O'Connell FP, O'Kelly P, Walshe JJ, Conlon P, et al. Acute interstitial nephritis: clinical features and response to corticosteroid therapy. Nephrol Dial Transplant. 2004;19(11):2778-83. https://doi.org/10.1 093/ndt/gfh485.

15. Elias TJ, Bannister KM, Clarkson AR, Faull D, Faull RJ. Clozapine-induced acute interstitial nephritis. Lancet. 1999;354(9185):1180-1. https://doi.org/1 0.1016/S0140-6736(99)01508-1.

16. Davey P, Gee S, Shergill SS. Inflammatory response to clozapine in the absence of myocarditis: case report. BJPsych open. 2016;2(3):244-6. https:// doi.org/10.1192/bjpo.bp.116.003228.

17. Štuhec M. Clozapine-induced elevated C-reactive protein and fever mimic infection. Gen Hosp Psychiatry. 2013;35(6):680-e5.

18. Duarte TA, Godinho FD, Ferreira AL, Simões do Couto F, Martins PT. Clozapine-Induced Procalcitonin Elevation. Prim Care Companion CNS Disord. 2017;19(3)

19. Cohen D, Correll CU. Second-Generation Antipsychotic-Associated Diabetes Mellitus and Diabetic Ketoacidosis: Mechanisms, Predictors, and Screening Need (ASCP Corner). J Clin Psychiatry. 2009;70(5):765.

20. Henderson DC, Cagliero E, Gray C, Nasrallah RA, Hayden DL, Schoenfeld DA, et al. Clozapine, diabetes mellitus, weight gain, and lipid abnormalities: a five-year naturalistic study. Am J Psychiatr. 2000;157(6):975-81. https://doi. org/10.1176/appi.ajp.157.6.975.

21. Ellison JC, Dufresne RL. A review of the clinical utility of serum clozapine and norClozapine levels. Mental Health Clinician. 2015;5(2):68-73. https:// doi.org/10.9740/mhc.2015.03.068.

22. de Leon J. Psychopharmacology: atypical antipsychotic dosing: the effect of smoking and caffeine. Psychiatr Serv. 2004;55(5):491-3. https://doi.org/10.11 76/appi.ps.55.5.491.

23. Carrillo JA, Herraiz AG, Ramos SI, Benitez J. Effects of caffeine withdrawal from the diet on the metabolism of clozapine in schizophrenic patients. J Clin Psychopharmacol. 1998;18(4):311-6. https://doi.org/10.1097/00004714-1 99808000-00011.

24. Jovanović M, Vučićević K, Miljković B. Understanding variability in the pharmacokinetics of atypical antipsychotics-focus on clozapine, olanzapine and aripiprazole population models. Drug Metab Rev. 2020;52(1):1-8. https://doi.org/10.1080/03602532.2020.1717517.

25. Hukkanen J, Puurunen J, Hyötyläinen T, Savolainen MJ, Ruokonen A, MorinPapunen $L$, et al. The effect of atorvastatin treatment on serum oxysterol concentrations and cytochrome P450 3A4 activity. Br J Clin Pharmacol. 2015;80(3):473-9. https://doi.org/10.1111/bcp.12701.

26. Andersson T, Hassan-Alin M, Hasselgren G, Röhss K. Drug interaction studies with esomeprazole, the (S)-isomer of omeprazole. Clin Pharmacokinet. 2001; 40(7):523-37. https://doi.org/10.2165/00003088-200140070-00004.

27. Feierman DE, Melinkov Z, Nanji AA. Induction of CYP3A by ethanol in multiple in vitro and in vivo models. Alcohol Clin Exp Res. 2003;27(6):981-8. https://doi.org/10.1111/j.1530-0277.2003.tb04424.x.

\section{Publisher's Note}

Springer Nature remains neutral with regard to jurisdictional claims in published maps and institutional affiliations. 